\title{
Poor Oral Health, That Is, Decreased Frequency of Tooth Brushing, Is Associated With Endothelial Dysfunction
}

\author{
Masato Kajikawa, MD; Ayumu Nakashima, MD, PhD; Tatsuya Maruhashi, MD, PhD;
}

Yumiko Iwamoto, MD; Akimichi Iwamoto, MD; Takeshi Matsumoto, MD; Takayuki Hidaka, MD, PhD; Yasuki Kihara, MD, PhD; Kazuaki Chayama, MD, PhD; Chikara Goto, PhD; Akira Taguchi, PhD; Kensuke Noma, MD, PhD; Yukihito Higashi, MD, PhD

\begin{abstract}
Background: Poor oral health is an independent predictor of cardiovascular outcome. Endothelial dysfunction is the initial step of atherosclerosis, resulting in cardiovascular outcomes; but there is no information on the association between oral health and endothelial function. The purpose of this study was to determine the relationships between oral health and endothelial function.
\end{abstract}

\begin{abstract}
Methods and Results: A total of 190 subjects who underwent health examinations (mean age, $57 \pm 18$ years), including patients with cardiovascular disease, completed a questionnaire on oral health and frequency of tooth brushing, and underwent measurement of vascular function, flow-mediated vasodilation (FMD) and nitroglycerine-induced vasodilation. The subjects were divided into 2 groups according to frequency of tooth brushing ( $\geq$ twice/day and <once/day). FMD was significantly lower in the <once/day tooth brushing group as compared to the $\geq$ twice/day tooth brushing group (3.3 $\pm 2.2 \%$ vs. $5.0 \pm 3.0 \%, \mathrm{P}<0.001)$. There was no significant difference in nitroglycerine-induced vasodilation between the 2 groups. On multiple logistic regression analysis, tooth brushing <once/day remained independently associated with low FMD tertile.
\end{abstract}

Conclusions: Poor oral health, that is, decreased frequency of tooth brushing, is associated with endothelial dysfunction. (Circ J 2014; 78: 950-954)

Key Words: Cardiovascular risk factor; Endothelial function; Flow-mediated vasodilation; Tooth brushing

C linical and epidemiological studies have shown a link between oral health, especially periodontitis, and cardiovascular disease, ${ }^{1-5}$ but controversy remains regarding the independent association between oral health and cardiovascular disease. ${ }^{5}$ Systemic inflammation induced by periodontal disease is thought to affect the development and maintenance of atherosclerosis through activation of a biochemical reaction cascade, initiation and development of plaque formation, and injury of the endothelium.

\section{Editorial p 837}

Flow-mediated vasodilation (FMD) as an index of endothe- lium-dependent vasodilation, and nitroglycerine-induced vasodilation as an index of endothelium-independent vasodilation in the brachial artery on high-resolution ultrasound, are useful for assessing vascular function. ${ }^{6-13}$ Endothelial dysfunction is the initial step of atherosclerosis, leading to the maintenance and progression of atherosclerosis, resulting in cardiovascular complications. ${ }^{14}$ Assessment of FMD is non-invasive and reflects nitric oxide (NO) production. In addition, previous studies have shown that endothelial function assessed using FMD can serve as an independent predictor of cardiovascular events. ${ }^{15-19}$

Recently, de Oliveira et al showed that poor oral health is associated with increasing risk of cardiovascular disease. ${ }^{20} \mathrm{Sev}-$ eral investigators, including us, have shown that periodontitis

Received October 28, 2013; revised manuscript received November 26, 2013; accepted December 11, 2013; released online February 5, 2014 Time for primary review: 21 days

Department of Cardiovascular Medicine (M.K., T. Maruhashi, Y.I., A.I., T. Matsumoto, T.H., Y.K.), Department of Gastroenterology and Metabolism, Applied Life Sciences (K.C.), Institute of Biomedical \& Health Sciencies, Hiroshima University, Hiroshima; Division of Regeneration and Medicine, Medical Center for Translational and Clinical Research, Hiroshima University Hospital, Hiroshima (A.N., K.N., Y.H.); Department of Cardiovascular Regeneration and Medicine, Research Institute for Radiation Biology and Medicine, Hiroshima University, Hiroshima (K.N., Y.H.); Hiroshima International University, Hiroshima (C.G.); and Department of Oral and Maxillofacial Radiology, Matsumoto Dental University, Shiojiri (A.T.), Japan

Mailing address: Yukihito Higashi, MD, PhD, FAHA, Department of Cardiovascular Regeneration and Medicine, Research Institute for Radiation Biology and Medicine (RIRBM), Hiroshima University, 1-2-3 Kasumi, Minami-ku, Hiroshima 734-8551, Japan. E-mail: yhigashi@ hiroshima-u.ac.jp

ISSN-1346-9843 doi:10.1253/circj.CJ-13-1330

All rights are reserved to the Japanese Circulation Society. For permissions, please e-mail: cj@j-circ.or.jp 


\begin{tabular}{|c|c|c|c|c|}
\hline Variable & Total $(n=190)$ & $<$ Once/day $(n=56)$ & $\geq$ Twice/day $(n=134)$ & P-value \\
\hline Age (years) & $57 \pm 18$ & $63 \pm 14$ & $55 \pm 20$ & 0.001 \\
\hline $\operatorname{Sex}(M / F)$ & $112 / 78$ & $48 / 8$ & $64 / 70$ & $<0.001$ \\
\hline BMI $\left(\mathrm{kg} / \mathrm{m}^{2}\right)$ & $23.6 \pm 4.0$ & $24.5 \pm 4.2$ & $23.1 \pm 3.8$ & 0.03 \\
\hline $\mathrm{SBP}(\mathrm{mmHg})$ & $132 \pm 21$ & $135 \pm 23$ & $130 \pm 20$ & 0.21 \\
\hline $\mathrm{DBP}(\mathrm{mmHg})$ & $77 \pm 14$ & $81 \pm 15$ & $75 \pm 14$ & 0.02 \\
\hline Heart rate (beats/min) & $70 \pm 13$ & $70 \pm 13$ & $70 \pm 13$ & 0.94 \\
\hline Total cholesterol (mg/dl) & $188 \pm 36$ & $183 \pm 30$ & $191 \pm 39$ & 0.17 \\
\hline Triglycerides (mg/dl) & $134 \pm 79$ & $130 \pm 87$ & $136 \pm 75$ & 0.71 \\
\hline $\mathrm{HDL}-\mathrm{C}(\mathrm{mg} / \mathrm{dl})$ & $58 \pm 16$ & $54 \pm 14$ & $59 \pm 16$ & 0.04 \\
\hline LDL-C (mg/dl) & $109 \pm 32$ & $108 \pm 26$ & $110 \pm 34$ & 0.66 \\
\hline Glucose (mg/dl) & $122 \pm 40$ & $115 \pm 33$ & $126 \pm 44$ & 0.13 \\
\hline hsCRP (mg/dl) & $0.11 \pm 0.26$ & $0.20 \pm 0.41$ & $0.06 \pm 0.06$ & 0.03 \\
\hline \multicolumn{5}{|l|}{ Medical history } \\
\hline Hypertension & $121(63.7)$ & $45(80.4)$ & $76(56.7)$ & 0.001 \\
\hline Dyslipidemia & $101(53.2)$ & $25(44.6)$ & $76(56.7)$ & 0.12 \\
\hline Diabetes mellitus & $55(28.9)$ & $20(35.7)$ & $35(26.1)$ & 0.18 \\
\hline Previous CAD & $28(14.7)$ & 8 (14.3) & $20(14.9)$ & 0.90 \\
\hline Previous stroke & $8(4.2)$ & $2(3.6)$ & $6(4.5)$ & 0.77 \\
\hline Smoker & $31(16.3)$ & $17(30.4)$ & $14(10.5)$ & 0.001 \\
\hline FMD (\%) & $4.5 \pm 2.9$ & $3.3 \pm 2.2$ & $5.0 \pm 3.0$ & $<0.001$ \\
\hline Nitroglycerine-induced vasodilation (\%) & $11.6 \pm 5.5$ & $11.6 \pm 5.7$ & $11.6 \pm 5.5$ & 0.99 \\
\hline
\end{tabular}

Data given as mean \pm SD or $\mathrm{n}(\%)$.

$\mathrm{BMI}$, body mass index; CAD, coronary artery disease; DBP, diastolic blood pressure; FMD, flow-mediated vasodilation; HDL-C, high-density lipoprotein cholesterol; hsCRP, high-sensitivity C-reactive protein; LDL-C, low-density lipoprotein cholesterol; SBP, systolic blood pressure.

is associated with endothelial dysfunction and that treatment of periodontitis improves endothelial function in patients with atherosclerosis as well as in healthy subjects. ${ }^{21-25}$ There is no information, however, on the association between oral health and endothelial function. We therefore investigated the relationship between oral health, frequency of tooth brushing, and vascular function in a general population of subjects who underwent a health-screening examination, including healthy subjects and patients with cardiovascular disease.

\section{Methods}

\section{Subjects}

Between March 2012 and June 2013, a total of 190 consecutive subjects (mean age, $57 \pm 18$ years) were recruited from people who underwent health-screening examinations at Hiroshima University Hospital. Hypertension was defined as systolic blood pressure $>140 \mathrm{mmHg}$ or diastolic blood pressure $>90 \mathrm{mmHg}$, in a sitting position, on at least 3 different occasions. Diabetes mellitus was defined according to the American Diabetes Association. ${ }^{26}$ Dyslipidemia was defined according to the third report of the National Cholesterol Education Program. ${ }^{27}$ The ethical committees in the present institutions approved the study protocol. Written informed consent for participation in the study was obtained from all subjects.

\section{Study Protocol}

We had a simple questionnaire about frequency of tooth brushing (<once/day and $\geq$ twice/day).

Subjects fasted the previous night for at least $12 \mathrm{~h}$. The study began at 08.30 A.M. The subjects were kept in the supine position in a quiet, dark, air-conditioned room (constant temperature, $22-25^{\circ} \mathrm{C}$ ) throughout the study. A 23 -gauge polyethylene cath- eter was inserted into the left deep antecubital vein to obtain blood samples. Thirty minutes after maintaining the supine position, FMD and nitroglycerine-induced vasodilation were measured. The observers were blind to the form of examination.

\section{Measurement of FMD}

The subjects remained supine throughout the study. The vascular response to reactive hyperemia in the brachial artery was used for assessment of endothelium-dependent FMD. A high-resolution linear artery transducer was coupled to computer-assisted analysis software (UNEXEF18G; UNEX Co, Nagoya, Japan) that used an automated edge detection system for measurement of brachial artery diameter. A blood pressure cuff was placed around the forearm. The brachial artery was scanned longitudinally $5-10 \mathrm{~cm}$ above the elbow. When the clearest B-mode image of the anterior and posterior intimal interfaces between the lumen and vessel wall was obtained, the transducer was held at the same point throughout the scan by a special probe holder (UNEX Co) to ensure consistency of the image. Depth and gain setting were set to optimize the images of the arterial lumen wall interface. When the tracking gate was placed on the intima, the artery diameter was automatically tracked, and the waveform of diameter changes over the cardiac cycle was displayed in real time using the FMD mode of the tracking system. This allowed the ultrasound images to be optimized at the start of the scan and the transducer position to be adjusted immediately for optimal tracking performance throughout the scan. Pulsed Doppler flow was assessed at baseline and during peak hyperemic flow, which was confirmed to occur within $15 \mathrm{~s}$ after cuff deflation. Blood flow velocity was calculated from the Doppler data and was displayed as a waveform in real time. The baseline longitudinal image of the artery was acquired for $30 \mathrm{~s}$, and then the blood pressure cuff was inflated to 


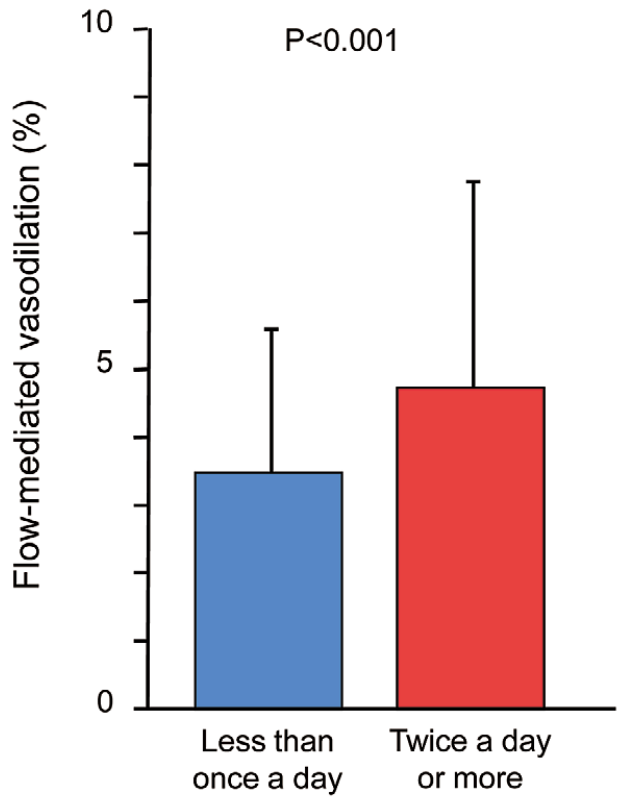

Frequency of tooth brushing

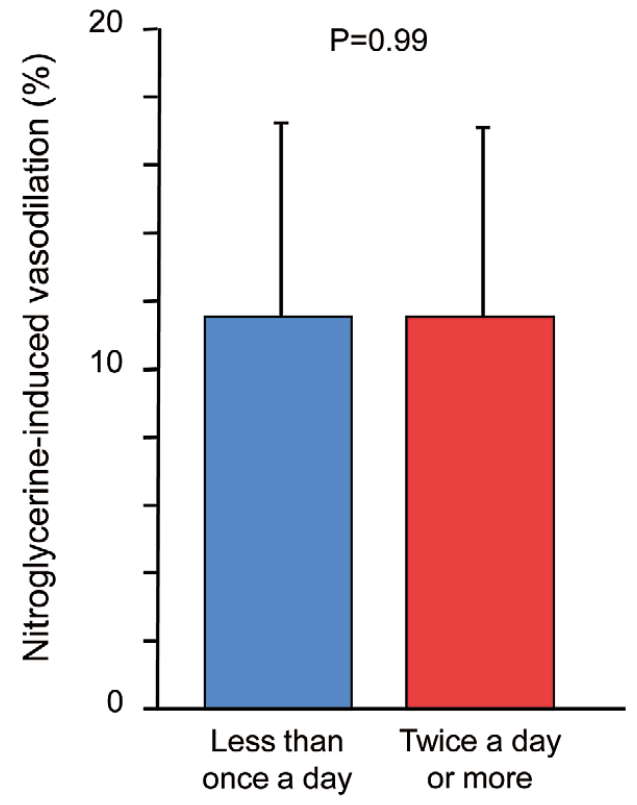

Frequency of tooth brushing

Figure. Flow-mediated vasodilation and nitroglycerine-induced vasodilation in the <once/day and $\geq t$ wice/day tooth brushing groups.

\begin{tabular}{lcc|}
\hline \multicolumn{1}{|c|}{ Table 2. Factors Associated With Low FMD Tertile } & $(<2.9 \%)$ \\
Parameters & OR (95\% Cl) & P-value \\
Intercept & & $<0.001$ \\
Age (1-year change) & $1.03(1.01-1.05)$ & 0.01 \\
Men & $1.39(0.67-2.93)$ & 0.38 \\
Diabetes mellitus (Yes) & $2.65(1.27-5.65)$ & 0.01 \\
<Once/day (Yes) & $2.26(1.07-4.81)$ & 0.03 \\
\hline
\end{tabular}

Output of a logistic regression model with FMD $>2.9 \%$ taken as the reference. Adjusted $r^{2}$ of the model was 0.14 . Initial factors included in the model were age, sex, dyslipidemia, diabetes mellitus, <once/day tooth brushing.

$\mathrm{Cl}$, confidence interval; OR, odds ratio. Other abbreviation as in Table 1.

$50 \mathrm{mmHg}$ above systolic pressure for $5 \mathrm{~min}$. The longitudinal image of the artery was recorded continuously until 5 min after cuff deflation. Pulsed Doppler velocity signals were obtained for $20 \mathrm{~s}$ at baseline and for $10 \mathrm{~s}$ immediately after cuff deflation. Changes in brachial artery diameter were immediately expressed as a percentage change relative to the vessel diameter before cuff inflation. FMD was automatically calculated as the percentage change in peak vessel diameter from baseline. Percentage of FMD (peak diameter-baseline diameter/baseline diameter) was used for analysis. Blood flow volume was calculated by multiplying the Doppler flow velocity (corrected for the angle) by heart rate and vessel cross-sectional area $\left(-\mathrm{r}^{2}\right)$. Reactive hyperemia was calculated as the maximum percentage increase in flow after cuff deflation compared with baseline flow.

The response to nitroglycerine was used for assessment of endothelium-independent vasodilation. After acquiring baseline rest image for $30 \mathrm{~s}$, a sublingual tablet (nitroglycerine $75 \mu \mathrm{g}$ ) was given and imaging of the artery was done continuously for
$5 \mathrm{~min}$. Nitroglycerine-induced vasodilation was automatically calculated as a percentage change in peak vessel diameter from baseline. Nitroglycerine percentage (peak diameter-baseline diameter/baseline diameter) was used for analysis. Inter- and intra-coefficients of variation for the brachial artery diameter were $1.6 \%$ and $1.4 \%$, respectively.

\section{Statistical Analysis}

Results are presented as mean \pm SD for continuous variables and as percentage for categorical variables. Statistical significance was set at $\mathrm{P}<0.05$. Comparison of continuous variables between 2 groups was performed using the Mann-Whitney U-test or the chi-squared test for categorical data. Stepwise multiple regression analysis was performed to find independent predictors of low FMD tertile $(<2.9 \%)$ among potential confounders $(\mathrm{P}<0.2)$ on univariate analysis. Using variables associated with low FMD tertile on stepwise multiple regression analysis, logistic regression analysis was then done. The data were processed using Stata version 9 (Stata, College Station, TX, USA).

\section{Results}

\section{Clinical Characteristics}

The baseline characteristics of the 190 subjects are listed in Table 1. Of the 190 subjects, 112 (58.9\%) were men and 78 $(41.1 \%)$ were women. One hundred and twenty-one $(63.7 \%)$ had hypertension, $101(53.2 \%)$ had dyslipidemia, 55 (28.9\%) had diabetes mellitus, and $31(16.3 \%)$ were current smokers. Of the 162 subjects who were evaluated, $28(14.7 \%)$ had known coronary artery disease and $8(4.2 \%)$ had known stroke.

\section{Vascular Function and Oral Health}

We divided the subjects into 2 groups according to frequency of tooth brushing (Table 1). There were significant differences 
between the 2 groups in age, sex, diastolic blood pressure, highdensity lipoprotein cholesterol, high-sensitivity C-reactive protein (hsCRP), prevalence of hypertension, and smoking. FMD was significantly lower in the <once/day tooth brushing group than in the $\geq$ twice/day tooth brushing group $(3.3 \pm 2.2 \%$ vs. $5.0 \pm 3.0 \%, \mathrm{P}<0.001$; Figure). There was no significant difference in nitroglycerine-induced vasodilation between the 2 groups. On multiple logistic regression analysis for low FMD tertile, age, diabetes mellitus and <once/day tooth brushing remained independently associated with low FMD tertile (Table 2).

\section{Discussion}

In the present study, we showed that poor oral health, that is, decreased frequency of tooth brushing is associated with endothelial dysfunction. These harmful effects on the vasculature may contribute to an increase in the prevalence of cardiovascular events in subjects with poor oral health. Tooth brushing $\geq$ twice/day is beneficial for not only oral health but also endothelial function, leading to improvement in public health and savings in health-care costs.

Cumulative cardiovascular risk contributes to the development of cardiovascular and cerebrovascular events. Hypertension, dyslipidemia, diabetes mellitus, aging, smoking, and obesity are contributing risk factors. In the present study, there were significant differences in cardiovascular risk factors, including age, prevalence of hypertension, and smoking status between, the low-frequency and high-frequency tooth brushing groups. After adjustment of cardiovascular risk factors, low frequency of tooth brushing remained an independent predictor of low FMD tertile. Therefore, low frequency of tooth brushing may simultaneously or independently affect the maintenance and progression of atherosclerosis. To our knowledge, this is the first report on the effect of oral health, that is, frequency of tooth brushing, on vascular function.

It is well known that there is a relationship between inflammation and oral health. In the present study, we confirmed results of previous studies showing that the inflammation marker CRP was significantly associated with poor oral health. ${ }^{24,25} \mathrm{An}$ association between inflammation and endothelial dysfunction has been suggested in many studies. ${ }^{21-25} \mathrm{We}$ previously showed that chronic systemic infection with Helicobacter pylori impaired endothelium-dependent vasodilation in healthy male subjects. ${ }^{28}$ Patients with periodontal disease are also ideal models for evaluating how endothelium-dependent vasodilation is affected by inflammation. Indeed, periodontal disease is associated with endothelial dysfunction. ${ }^{21-25}$ We have also shown that periodontal therapy improves endothelium-dependent vasodilation in patients with periodontitis. ${ }^{24,25}$ These findings suggest that endothelial dysfunction observed in the poor oral health group is due to increase in systemic inflammation and that oral health care, including tooth brushing, may have a beneficial effect on endothelial function.

Chronic inflammation induced by poor oral health may contribute to endothelial dysfunction through a decrease in NO bioavailability, a decrease in $\mathrm{NO}$ production and/or an increase in NO inactivation. Under the condition of chronic systemic inflammation, production of pro-inflammatory cytokines downregulates the expression of endothelial NO synthase (eNOS) and decreases the half-life of eNOS mRNA. ${ }^{29,30}$ Interestingly, these cytokines attenuate endothelium-dependent vasodilation in vivo. ${ }^{31} \mathrm{CRP}$ also directly decreased eNOS mRNA and protein levels and enzymatic activity in human aortic endothelial cells. ${ }^{32}$ It is thought that endothelial dysfunction causes inflammation of the vascular wall, leading to a vicious circle between endothelial dysfunction and inflammation. These findings suggest that poor oral health activates several pro-inflammatory pathways, resulting in downregulation of the expression of eNOS and decrease in enzymatic activity and NO production.

\section{Study Limitations}

Although the method of self-reported assessment for dental status is well established, we used a questionnaire on the frequency of tooth brushing at the time of FMD measurement.

It is thought that lifestyle modifications, including physical activity and diet status, impair endothelial function, leading to cardiovascular outcomes. ${ }^{33-36}$ Unfortunately, in the present study, we did not obtain data on exercise status and diet. We cannot deny the possibility that differences in frequency of exercise and/or dietary fish intake affect the differences in FMD between patients with more and less frequent tooth brushing.

Not only the frequency of tooth brushing but also the quality and quantity of tooth brushing may influence FMD. Tooth brushing only once a day but done carefully and thoroughly at night immediately before bed might be more effective than poor tooth brushing twice a day for a short time. Evaluation of the effects of both quality and quantity of tooth brushing on vascular function would enable more specific conclusions to be drawn.

\section{Conclusions}

Poor oral health, that is, frequency of tooth brushing, is associated with endothelial dysfunction. Tooth brushing is a simple approach for improving poor oral condition, and it is expected that appropriate oral health care will improve endothelial function. Future large-scale clinical studies are needed to confirm whether long-term tooth brushing $\geq$ twice/day improves vascular function and reduces mortality and morbidity of cardiovascular disease in subjects with poor oral health.

\section{Acknowledgments}

We thank Miki Kumiji, Megumi Wakisaka, Ki-ichiro Kawano, and Satoko Michiyama for their excellent assistance with the manuscript. This study was supported in part by a Grant-in-Aid for Scientific Research from the Ministry of Education, Science and Culture of Japan (1859081500 and 21590898).

\section{Disclosures}

Financial disclosures: None.

\section{References}

1. Paunio K, Impivaara O, Tiekso J, Mäki J. Missing teeth and ischaemic heart disease in men aged 45-64 years. Eur Heart J 1993; 14 (Suppl K): 54-56.

2. Joshipura KJ, Rimm EB, Douglass CW, Trichopoulos D, Ascherio A, Willett WC. Poor oral health and coronary heart disease. J Dent Res 1996; 75: 1631-1636.

3. Beck JD, Elter JR, Heiss G, Couper D, Mauriello SM, Offenbacher S. Relationship of periodontal disease to carotid artery intima-media wall thickness: The atherosclerosis risk in communities (ARIC) study. Arterioscler Thromb Vasc Biol 2001; 21: 1816-1822.

4. Desvarieux M, Demmer RT, Rundek T, Boden-Albala B, Jacobs DR Jr, Sacco RL, et al. Periodontal microbiota and carotid intima-media thickness: The Oral Infections and Vascular Disease Epidemiology Study (INVEST). Circulation 2005; 111: 576-582.

5. Lockhart PB, Bolger AF, Papapanou PN, Osinbowale O, Trevisan M, Levison ME, et al. Periodontal disease and atherosclerotic vascular disease: Does the evidence support an independent association? A scientific statement from the American Heart Association. Circulation 2012; 125: 2520-2544.

6. Celermajer DS, Sorensen KE, Gooch VM, Spiegelhalter DJ, Miller OI, Sullivan ID, et al. Non-invasive detection of endothelial dysfunction in children and adults at risk of atherosclerosis. Lancet 1992; 340: $1111-1115$.

7. Celermajer DS, Sorensen KE, Bull C, Robinson J, Deanfield JE. 
Endothelium-dependent dilation in the systemic arteries of asymptomatic subjects relates to coronary risk factors and their interaction. J Am Coll Cardiol 1994; 24: 1468-1474.

8. Benjamin EJ, Larson MG, Keyes MJ, Mitchell GF, Vasan RS, Keaney $\mathrm{JF}$ Jr, et al. Clinical correlates and heritability of flow-mediated dilation in the community: The Framingham Heart Study. Circulation 2004; 109: $613-619$.

9. Idei N, Nishioka K, Soga J, Hidaka T, Hata T, Fujii Y, et al. Vascular function and circulating progenitor cells in thromboangiitis obliterans (Buerger's disease) and atherosclerosis obliterans. Hypertension 2011; 57: 70-78.

10. Soga J, Noma K, Hata T, Hidaka T, Fujii Y, et al; ROCK Study Group. Rho-associated kinase activity, endothelial function, and cardiovascular risk factors. Arterioscler Thromb Vasc Biol 2011; 31: 2353-2359.

11. Fujimura N, Noma K, Hata T, Soga J, Hidaka T, et al; ROCK Study Group. Mineralocorticoid receptor blocker eplerenone improves endothelial function and inhibits rho-associated kinase activity in patients with hypertension. Clin Pharmacol Ther 2012; 91: 289-297.

12. Adams MR, Robinson J, McCredie R, Seale JP, Sorensen KE, Deanfield JE, et al. Smooth muscle dysfunction occurs independently of impaired endothelium-dependent dilation in adults at risk of atherosclerosis. J Am Coll Cardiol 1998; 32: 123-127.

13. Raitakari OT, Seale JP, Celermajer DS. Impaired vascular responses to nitroglycerin in subjects with coronary atherosclerosis. Am J Cardiol 2001; 87: 217-219.

14. Ross R. Atherosclerosis: An inflammatory disease. NEngl J Med 1999; 340: $115-126$

15. Modena MG, Bonetti L, Coppi F, Bursi F, Rossi R. Prognostic role of reversible endothelial dysfunction in hypertensive postmenopausal women. J Am Coll Cardiol 2002; 40: 505-510.

16. Gokce N, Keaney JF Jr, Hunter LM, Watkins MT, Menzoian JO, Vita JA. Risk stratification for postoperative cardiovascular events via noninvasive assessment of endothelial function: A prospective study. Circulation 2002; 105: 1567-1572.

17. Brevetti G, Silvestro A, Schiano V, Chiariello M. Endothelial dysfunction and cardiovascular risk prediction in peripheral arterial disease: Additive value of flow-mediated dilation to ankle-brachial pressure index. Circulation 2003; 108: 2093-2098.

18. Lerman A, Zeiher AM. Endothelial function: Cardiac events. Circulation 2005; 111: 363-368.

19. Yeboah J, Folsom AR, Burke GL, Johnson C, Polak JF, Post W, et al. Predictive value of brachial flow-mediated dilation for incident cardiovascular events in a population-based study: The multi-ethnic study of atherosclerosis. Circulation 2009; 120: 502-509.

20. de Oliveira C, Watt R, Hamer M. Toothbrushing, inflammation, and risk of cardiovascular disease: Results from Scottish Health Survey. BMJ 2010; 340: c2451.

21. Amar S, Gokce N, Morgan S, Loukideli M, Van Dyke TE, Vita JA. Periodontal disease is associated with brachial artery endothelial dysfunction and systemic inflammation. Arterioscler Thromb Vasc Biol 2003; 23: $1245-1249$.

22. Blum A, Kryuger K, Mashiach Eizenberg M, Tatour S, Vigder F,
Laster Z, et al. Periodontal care may improve endothelial function. Eur J Intern Med 2007; 18: 295-298.

23. Tonetti MS, D'Aiuto F, Nibali L, Donald A, Storry C, Parkar M, et al. Treatment of periodontitis and endothelial function. $N$ Engl J Med 2007; 356: 911-920.

24. Higashi Y, Goto C, Jitsuiki D, Umemura T, Nishioka K, Hidaka T, et al. Periodontal infection is associated with endothelial dysfunction in healthy subjects and hypertensive patients. Hypertension 2008; 51: $446-453$.

25. Higashi Y, Goto C, Hidaka T, Soga J, Nakamura S, Fujii Y, et al. Oral infection-inflammatory pathway, periodontitis, is a risk factor for endothelial dysfunction in patients with coronary artery disease. Atherosclerosis 2009; 206: 604-610.

26. American Diabetes Association. Clinical practice recommendations 1999. Diabetes Care 1999; 22 (Suppl 1): S1-S114.

27. Expert Panel on Detection, Evaluation, and Treatment of High Blood Cholesterol in Adults. Executive Summary of the Third Report of the National Cholesterol Education Program (NCEP) Expert Panel on Detection, Evaluation, and Treatment of High Blood Cholesterol in Adults (Adult Treatment Panel III). JAMA 2001; 285: 2486-2497.

28. Oshima T, Ozono R, Yano Y, Oishi Y, Teragawa H, Higashi Y, et al. Association of helicobacter pylori infection with systemic inflammation and endothelial dysfunction in healthy male subjects. $J$ Am Coll Cardiol 2005; 45: 1219-1222.

29. Kofler S, Nickel T, Weis M. Role of cytokines in cardiovascular diseases: A focus on endothelial responses to inflammation. Clin Sci (Lond) 2005; 108: 205-213.

30. Yoshizumi M, Perrella MA, Burnett JC Jr, Lee ME. Tumor necrosis factor downregulates an endothelial nitric oxide synthase mRNA by shortening its half-life. Circ Res 1993; 73: 205-209.

31. Hagat K, Vallance P. Inflammatory cytokines impair endotheliumdependent dilatation in human veins in vivo. Circulation 1997; 96: $3042-3047$

32. Venugopal SK, Devaraj S, Yuhanna I, Shaul P, Jialal I. Demonstration that C-reactive protein decreases eNOS expression and bioactivity in human aortic endothelial cells. Circulation 2002; 106: 1439-1441.

33. Heinzelmann F, Bagley RW. Response to physical activity programs and their effects on health behavior. Public Health Rep 1970; 85: 905-911.

34. Poltavski D, Holm J, Vogeltanz-Holm N, McDonald L. Assessing health-related quality of life in Northern Plains American Indians: Prominence of physical activity as a health behavior. Am Indian Alsk Native Ment Health Res 2010; 17: 25-48.

35. Matsuzawa Y, Sugiyama S, Sugamura K, Sumida H, Kurokawa H, Fujisue K, et al. Successful diet and exercise therapy as evaluated on self-assessment score significantly improves endothelial function in metabolic syndrome patients. Circ J 2013; 77: 2807-2815.

36. Veijalainen A, Tompuri T, Laitinen T, Lintu N, Viitasalo A, Laaksonen $\mathrm{DE}$, et al. Metabolic risk factors are associated with stiffness index, reflection index and finger skin temperature in children: Physical Activity and Nutrition in Children (PANIC) study. Circ J 2013; 77: $1281-1288$ 